\title{
Geological and Mineralogical mapping in Moroccan central Jebilet using multispectral and hyperspectral satellite data and Machine Learning
}

\author{
Mohcine Chakouri, Abderrazak El Harti, Rachid Lhissou, Jaouad El Hachimi, Amine Jellouli \\ Team of Remote Sensing and GIS Applied to Geosciences and Environment, Faculty of Sciences and \\ Techniques, PO BOX. 523 Beni Mellal, Morocco, chakouri.mohcine@gmail.com
}

\begin{abstract}
The Central Jebilet Massif is one of the main Palaeozoic outcrops in Morocco. This massif is characterized by its arid climate, its significant mining potential and the absence of plant cover, which favors the use of spatial remote sensing for geological mapping and mineral prospecting in this site. The objective of this study is the comparison of hyperspectral data from the Hyperion sensor of the Earth Observing-1 (EO-1) satellite and multispectral data from the Operational Land Imager (OLI) sensor of Landsat 8 in the discrimination of geological units and detection of iron caps in the study area. The classification by the Support Vector Machine (SVM) method allowed for a good mapping of the lithological units in the study area. The accuracy of the SVM classification of hyperspectral data is higher than that of multispectral data, which was demonstrated by the confusion matrix, notably an overall accuracy of $93.05 \%$ and $89.24 \%$, respectively, and a kappa coefficient of $91.25 \%$ and $84.36 \%$, respectively. Concerning the iron detection, the band rationing using both sensors have demonstrated a performance of detecting areas that contain more iron ores, especially, the iron caps of Kettara mine, with a small advantage of hyperspectral data. In overall, our results highlight the efficiency of machine learning classifier and hyperspectral data for the detection of iron ores and the discrimination of lithological units in arid regions. The use of hyperspectral and multispectral images has been shown to be a good technique for the characterization of iron deposits and lithological units, which may help in in mineral exploration engineering with reduced fieldwork and geochemistry.
\end{abstract}

Key words: Central Jebilet, Geological mapping, Hyperion, OLI, SVM.

\section{INTRODUCTION}

The Central Jebilet, Marrakech, Morocco, provides an excellent example of a complex mineral system rich in geological mapping studies already carried out in the area using conventional in-situ mapping $[1,2]$ and multispectral remote sensing and hyperspectral spectroradiometry between 350 and $2500 \mathrm{~nm}$ [3-6]. In fact, the spectral signatures of schist, acidic, basic and ultrabasic rocks and iron cap rocks were analyzed in the laboratory by [6] using an ASD spectroradiometer with a view to employing hyperspectral remote sensing for geological and mineralogical mapping of the region. This study site was chosen because of its lithological diversity, mineralogical richness and lack of vegetation cover, which is very favorable for remote sensing studies applied to geology and mineralogical mapping [7-9]. It presents a schist series dating from the Upper Viseen (Sarhlef schist), basic and acid magmatic intrusions and sulphide cluster mineralization that materialize by iron caps, these elements appear at the surface and are difficult to identify visually [5]. Satellite data has become a practical and cost-effective information in geological engineering, especially in areas where conventional geological mapping methods require a large investment of resource (time and staff) and in high-risk or difficult-to-access terrain [10-14]. Each material in particular minerals in rocks and soils can be characterized by spectral windows of absorption in the electromagnetic spectrum [15-17]. They have significant absorption spectral characteristics in visible, Near Infrared (VNIR) and Short Wave Infrared (SWIR) [18-23] and sometimes in the thermal infrared region [24]. These characteristics, which have been studied since the 1970s, are diagnostic indicators for accurately measuring the mineralogy and lithology of continental surfaces [25-29]. It is thus possible to locate potential deposits that cannot be detected by conventional prospecting methods (such as aeromagnetism) by mapping marker minerals that are easy to identify by their spectral signatures, but difficult to map directly in the field [30]. Several studies have demonstrated the usefulness of using multispectral and hyperspectral images for lithological and mineralogical mapping using ratio calculation techniques and geological interpretation of images [27, 30-36]. The low spectral resolution of multispectral satellite imagery limits the ability to extract information on surface mineralogy. The high spectral resolution of hyperspectral imagery can improve the discrimination of different rock types [37-41]. In fact, many 
classification methods have been developed to classify a remote sensing image. The research of [42] presents an explanatory review of the major classification methods. The objective of this study is firstly, the evaluation of the performance of the data from the two sensors OLI and Hyperion, and secondly, the evaluation of the contribution of the machine learning classification Support Vector Machines (SVM) in the discrimination of the lithological units in our study area and finally, the development of a spectral index that allows for the detection of iron ores based on the absorption window in the near and Short Wave Infrared spectrum in the Hyperion and Landsat OLI image. This index will undoubtedly allow further exploration of new mines.

\section{MATERIAL AND METHODS}

\subsection{Study area}

The Jebilet massif is located between latitudes $\left(31^{\circ} 40^{\prime \prime} \mathrm{N}\right.$, $\left.32^{\circ} \mathrm{N}\right)$ and longitudes $\left(8^{\circ} 20^{\prime \prime} \mathrm{W}, 7^{\circ} 40^{\prime \prime} \mathrm{W}\right)$ about $8 \mathrm{~km}$ north of Marrakech. It extends in an east-west direction, over a length of $170 \mathrm{~km}$ and a width of 7 to $40 \mathrm{~km}$. It is bordered to the north by the Bahira plain, to the south by the Haouz plain, to the east by the Atlas of Beni Mellal and to the west by the Jurassic-Cretaceous Mouissat hills (Error! Reference source not found.). The Central Jebilet are composed of schists, limestones and conglomerates that range in age from
Cambrian to Carboniferous. They are also formed from a schist series dated to the Upper Viséan (Sarhlef schist), which is the dominant geological unit in this region. Volcanic activities have left traces in the form of small basic and acid magmatic intrusions to considerable extent. Noting well the presence of sulphide cluster mineralization that materializes at the surface by iron caps.

\subsection{Data Used}

The image data used in this study are: a multispectral image acquired by the OLI sensor dated 08 May 2014 and a hyperspectral image from the Hyperion sensor dated 23 May 2005. The OLI image is used only with 6 out of 9 bands from the visible to the mid-infrared by eliminating the aerosol band, the cirrus band and the panchromatic band. In the Hyperion image, the eliminated bands are in the VNIR from 1 to 7,58 to 70 and in the SWIR from 71 to 76 , from 225 to 242 which correspond to weak or failing detectors [43], Bands 77 and 78 have also been deleted as they are areas of overlap between VNIR and SWIR [44]. In addition, the central Jebilet geological and mineralization map at $1 / 100,000$ were used to validate the results, Table 1 describes the satellite data used in this study

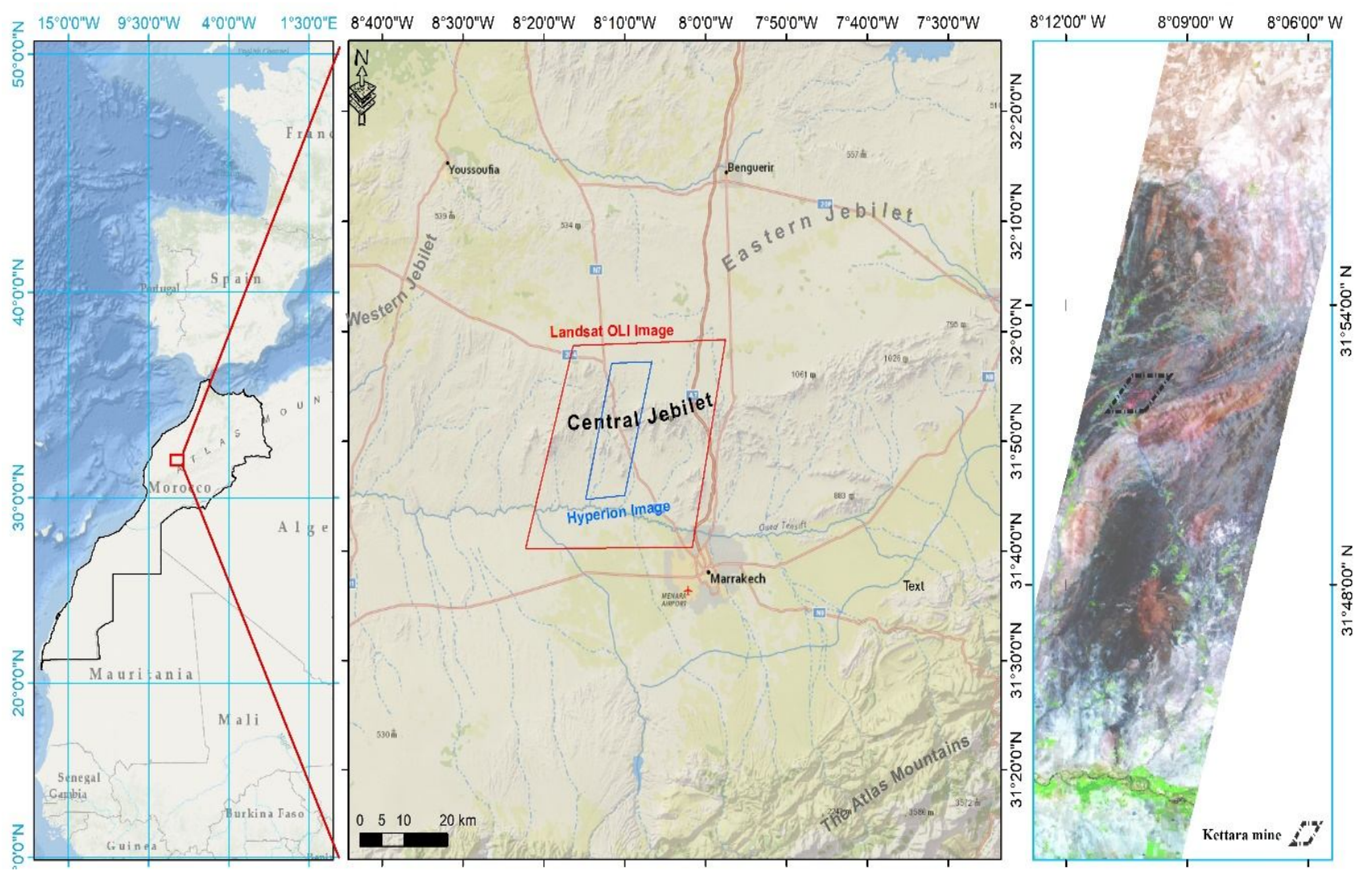

Figure 1: (A): Location of our study area, and the Hyperion subset covering the studied area of central Jebilet with false color composite composed of R, 146; B, 50; G, 30. 
Table 1: The spectral bands resulting from the different stages of pre-processing (Landsat OLI, Hyperion):

\begin{tabular}{ccc}
\hline Band & Wavelength $(\mathbf{n m})$ & Resolution $(\mathbf{m})$ \\
\hline Hyperion & & \\
$\mathbf{1 1 - 5 5}$ & $457.34-905.05$ & 30 \\
$\mathbf{8 0 - 9 6}$ & $942.72-1104.18$ & 30 \\
$\mathbf{1 0 1 - 1 3 4}$ & $1154.57-1487.53$ & 30 \\
$\mathbf{1 3 6 - 1 9 9}$ & $1507.72-2143.33$ & 30 \\
$\mathbf{2 0 4 - 2 1 5}$ & $2193.72-2304.71$ & 30 \\
$\mathbf{2 2 1 - 2 2 4}$ & $2365.20-2395.50$ & 30 \\
Landsat OLI & & \\
$\mathbf{2}$ & $450-515$ & 30 \\
$\mathbf{3}$ & $525-600$ & 30 \\
$\mathbf{4}$ & $630-680$ & 30 \\
$\mathbf{5}$ & $845-885$ & 30 \\
$\mathbf{6}$ & $1560-1660$ & 30 \\
$\mathbf{7}$ & $2100-2300$ & 30
\end{tabular}

\subsection{Methodology}

Hyperspectral data make image interpretation more difficult due to redundant information, and given the need for radiometric calibration and atmospheric correction of both sensors and the problem of dimensionality in Hyperion data [45], it is necessary to go through pre-processing before any image analysis. Figure 2 illustrates the methodology followed in this study.

\subsection{Image Data Pre-Processing}

Atmospheric and radiometric corrections are necessary steps in the satellite image processing process [23]. They aim to subtract the signal induced by atmospheric effects (absorption and scattering) from the signal measured at the sensor in order to obtain a "true" signal. First, the radiometric correction was performed by transforming the digital number into apparent reflectance. Second, the atmospheric correction consists of transforming the apparent reflectance into ground reflectance. The atmospheric correction of the Landsat OLI and Hyperion images was done by the FLAASH (Fast Lineof-Sight Atmospheric Analysis of Spectral Hypercubes) method implemented in the Envi software (Version 5.3).

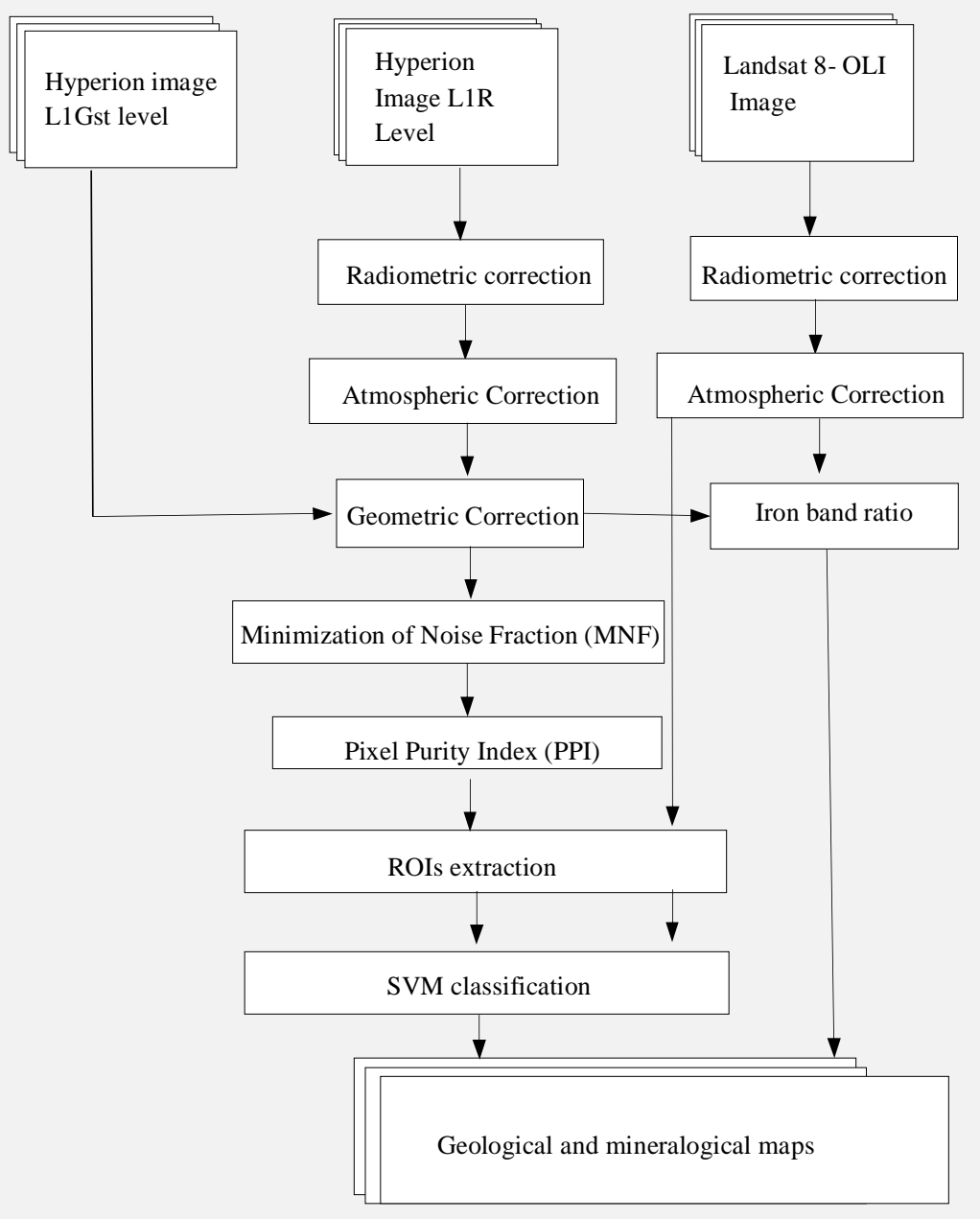

Geological dataset

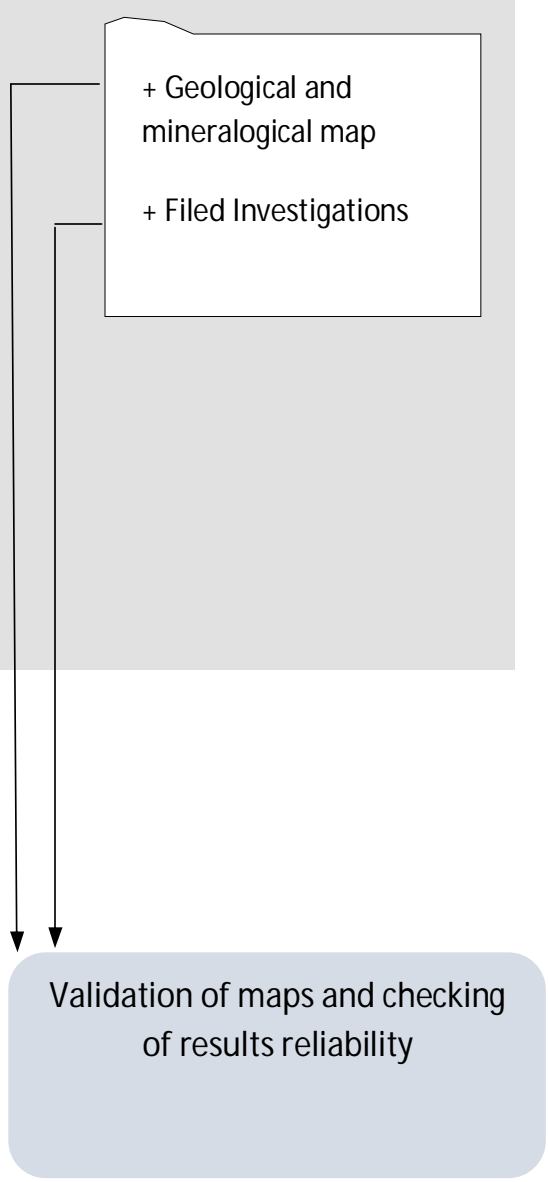

Figure. 1 : Methodology flowchart 
FLAASH is based on the MODTRAN (MODerate resolution atmospheric TRANsmission) radiative transfer model [23, 46-48] and widely used for hyperspectral images [49, 50]. Figure 3 shows the difference between the spectra before and after the atmospheric correction of OLI data, while Figure 4 shows the effect of the correction on the hyperspectral image.

The Hyperion image contains high-frequency errors (vertical stripes or vertical striations) on the image bands. In the L1R product, these bands are left unmodified, allowing users to manage or replace bad pixels. In the present study, an attempt was made to visually identify these bad columns, and then develop a patch in the form of a filter and then apply a Flag Mask function to remove large striations [43, 51]. The correction filter used is a low-pass filter that preserves low frequencies, while targeting the wrong columns in each band, and replacing them with the average of the $3 \times 3$ neighbourhood [52].

\subsection{Minimum Noise Fractions (MNF)}

The MNF transformation is used to determine the inherent dimensionality of the image (the pertinent information), to separate the noise in the data and to reduce the spectral dimensions that will be analyzed later $[53,54]$. It is modified by [55] and implemented in ENVI software. It consists essentially of two main transformations as follows; the first based on an estimated noise covariance matrix by applying decorrelation and scaling in the data, and the second consists of a standard principal component transformation [14, 23].

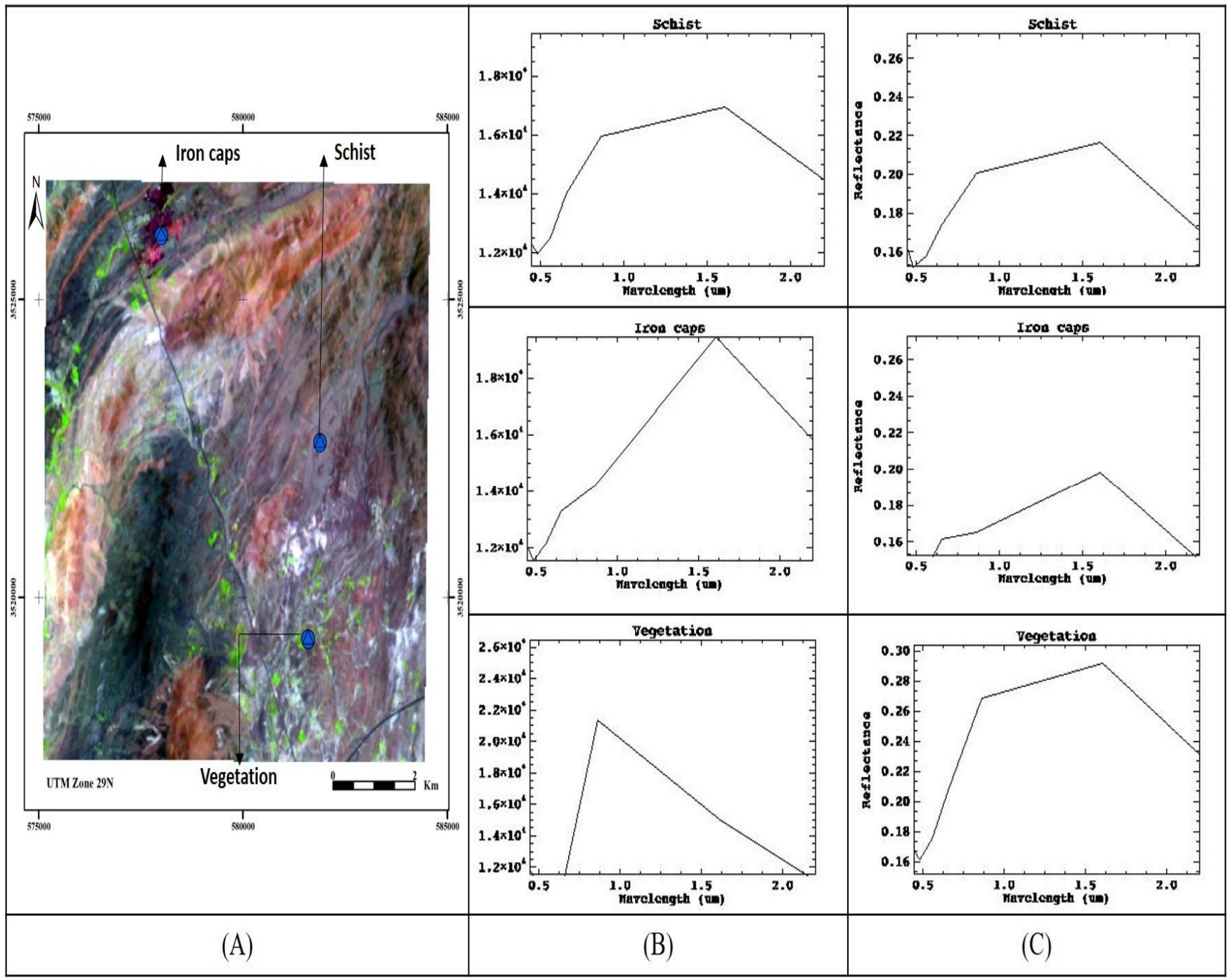

Figure 3: Spectral signatures before and after atmospheric correction of the Landsat-8 OLI image: $(A)$ OLI image in false color $(R=6, G=5$, $B$ =4); (B) Spectral profiles before atmospheric correction (C) Spectral profiles after DOS (reflectance). 


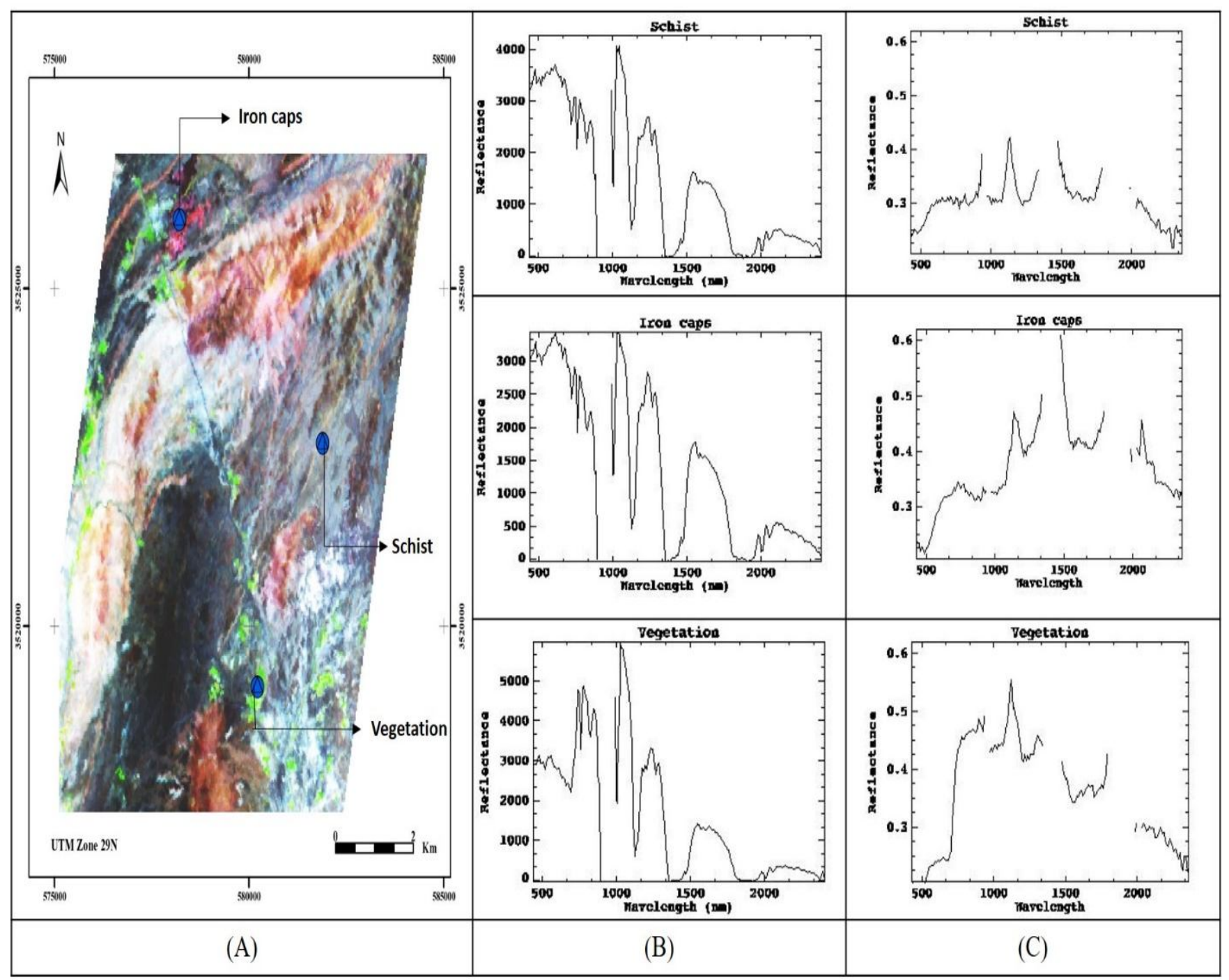

Figure 4: The spectral signatures before and after atmospheric correction of the hyperspectral image: $(\mathrm{A})$ Hyperion in false color image (R = $146, \mathrm{G}=50, \mathrm{~B}=30$ ); (B) spectral profiles before atmospheric correction $(\mathrm{C})$ spectral profiles after FLAASH (reflectance).

\subsection{Pixel Purity Index (PPI)}

Next comes the extraction of the pure pixels (Endmember) which will then present the regions of interest to be integrated in the SVM classification. This step is fundamental for the supervised classification of the image. The Pixel Purity Index (PPI) indicates the location of the purest pixels in the image [56-59]. By definition, a pure pixel is one that contains a single spectral material and therefore a single spectral signature. However, due to the spatial resolution of the Hyperion and OLI sensors $(30 \mathrm{~m})$, most pixels contain mixtures of materials resulting in a spectral mixture.

\subsection{SVM Classifier}

The Support Vector Machine classification is a supervised machine learning classification based on the choice of regions of interest previously extracted for the OLI and Hyperion image. It is a supervised non-parametric statistical technique [60-65]. SVM is based essentially on the adaptation of the hyperplane separator, which offers the best separation between the two classes in a multidimensional space. This hyperplane is the decision surface on which the optimal separation of the classes will take place[66]. The distance between the two classes separated by the hyperplane is named Margin [67]. Thus, in general, the larger the margin, the lower the misclassification error [68, 69], in our study we used a non-linear SVM classification with the kernel of the radial base function (RBF), which is widely used and gives better results compared to other grains (linear, polynomial or Gaussian) in agriculture [70] and in other applications [71]. The SVM equation for the classification of two classes of information is given as follows [72] :

$$
f(x)=\operatorname{sign}\left(\Sigma N \alpha_{i} y_{i}, K\left(x, x_{i}\right)+b\right)
$$

Where $x_{i}$ is a support vector for formation case $i, y_{i}$ is the label of the information class, $\mathrm{K}\left(\mathrm{x}, \mathrm{x}_{\mathrm{i}}\right)$ is the function of the kernel, $\mathrm{b}$ is the intercept constant, $\mathrm{N}$ is the number of support 
vectors and $\alpha_{i}$ are constants determined by maximization. The kernel used is therefore as follows:

$$
\kappa\left(x_{i}, x_{j}\right)=\exp \left(-g\left\|x_{i}-x_{j}\right\|^{2}\right), g>0
$$

Where $\mathrm{g}$ is the gamma term in the RBF kernel, which must be predefined by the user as input. In addition, the penalty parameter $\mathrm{C}$ for the SVM algorithm must also be predefined. Increasing the value of $\mathrm{C}$ increases the cost of misclassifying points and leads to the creation of a more accurate SVM model. Thus, the selected value is high and equal to 100 . Concerning the $\mathrm{g}$ value, the inverse of the number of bands is a reasonable but not perfect choice, since the gamma value controls the transformation of input data in a highdimensional space [73].

\subsection{Iron Spectral Index}

The study carried out for the extraction of the iron caps is based firstly on the spectral signature extracted by a spectroradiometric study of the elements that exist in the study area [6] and secondly on the absorption feature of the minerals (Hematite and Geothite) which is in the near infrared. So we tried to make an index based on the $\mathrm{Fe}^{3+}$ absorption feature in the $850-1300 \mathrm{~nm}$ part of the spectrum by performing mathematical operations on the different bands of this part of the spectrum (Figure5).

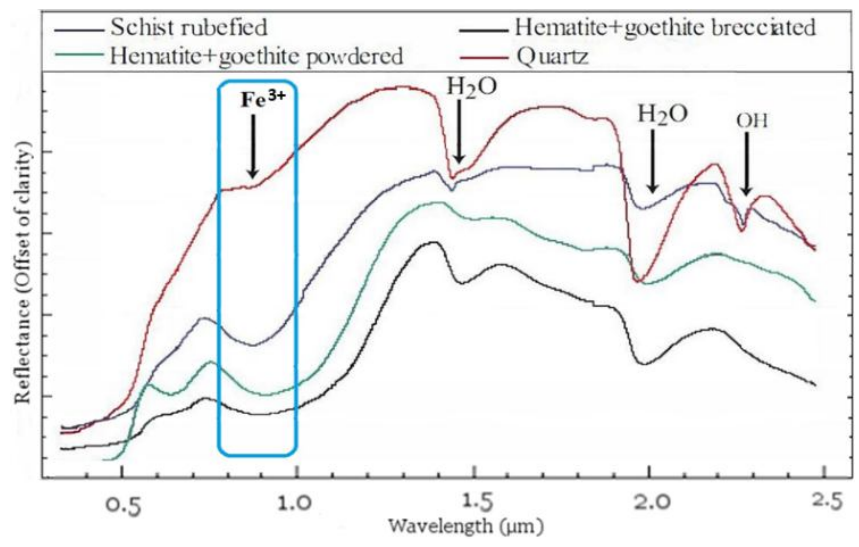

Figure 5 : Iron absorption window [6]

\section{RESULTS AND DISCUSSIONS}

\subsection{Image data enhancements}

After having eliminated the black columns (stripes) by applying a $3 \times 3$ filter, we used the Flag Mask function [51] to completely eliminate scratches. Figure 6 shows the enhancement of the affected bands in the Hyperion image.

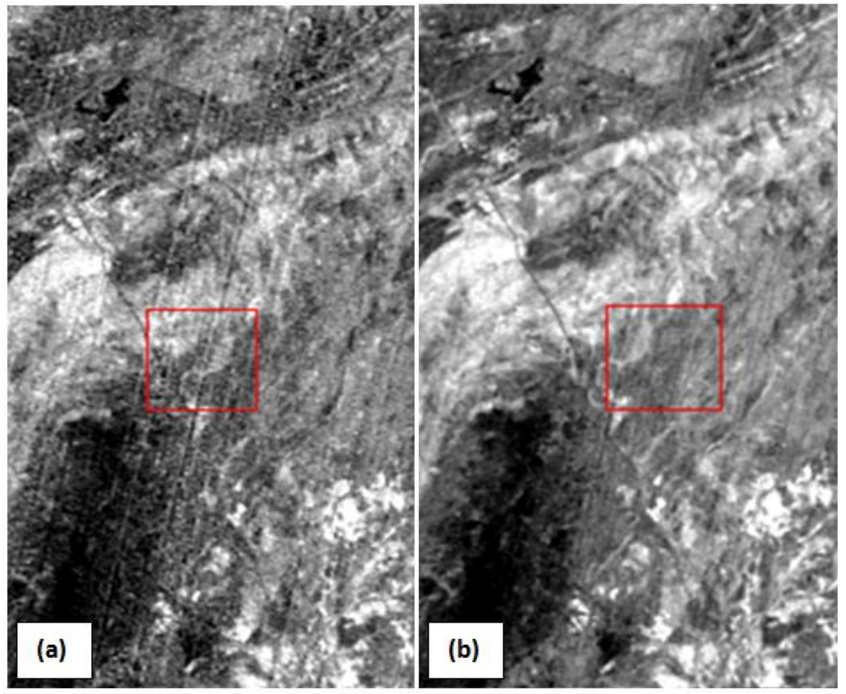

Figure 6: Stripe removal for Hyperion image by Flag Mask, (a) band $\mathrm{N}^{\circ} 99$ with vertical stripes before Flag Mask. (b) Same band after Flag Mask

Then, atmospheric correction of the two images (OLI and Hyperion) resulted in a slight decrease in reflectance in the visible, particularly blue, and a slight increase in reflectance in the infrared bands. These findings reflect corrections to the radiometry of the image, the effects of short wavelength scattering and absorption in the infrared.

\subsection{Geological Mapping with SVM Classifier}

For the Hyperion image, the prototype spectral signatures were extracted using ENVI software using the Image MNF Transform, which allows for the separation of noise in the spectral bands that will be analyzed in the subsequent pure pixel (Endmembers) extraction for each selected class. As for the OLI image, the extraction of the ROIs was based on a field visit, the geological map and subsequent studies [5, 6, 74]. This step is fundamental for the SVM classification of the image. Figure 7 illustrates the location of the regions of interest on the Hyperion image that were used in the SVM classification.

Endmembers of selected rocks are used for classification by the SVM method. SVM has been implemented using radial basis function (RBF) as classification kernel parameter. We chose the RBF kernel because it is known to produce generally good results $[60,68]$. Based on the generated prototype signatures (endmembers), SVM has mapped 7 classes: iron caps, shale, alluvium, basic volcanic, acid volcanic, metamorphic field and a vegetation class. 


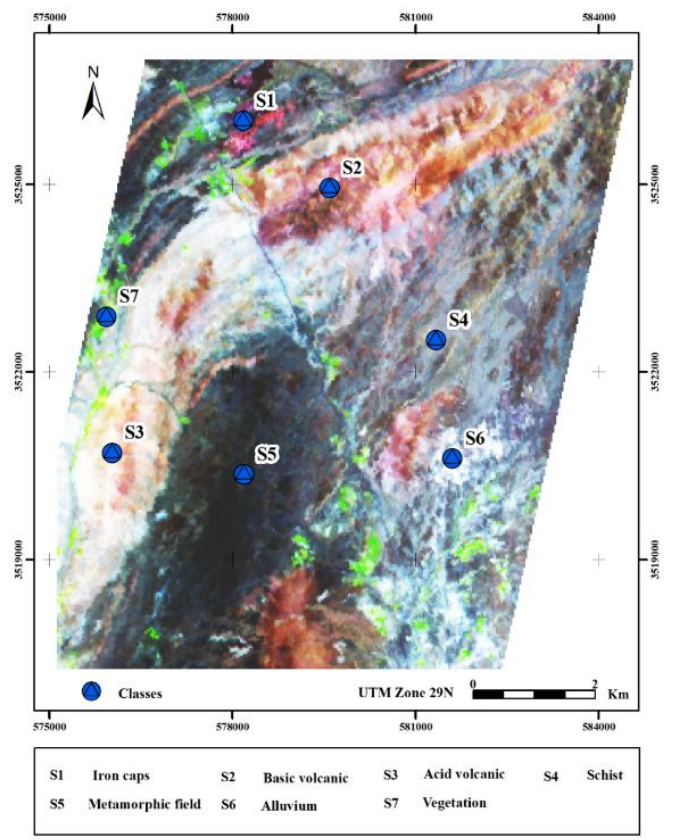

Figure 7: Location of regions of interest
The SVM maps in Figure 8 showed a small area of very rich iron mineralization and schist dominance in the region. Classes related to volcanic activity have been mapped as small to very large basic and acid magmatic bodies. Visual comparison of the two maps shows that the map from the OLI image underestimates the ferruginous surface with a small exaggeration of the acid volcanic surfaces.

Regions of interest in the field and the geological map of the area were used to validate the SVM classification results. The validation was done by a direct confrontation with the ground truth by calculating the confusion matrix between the classes of the maps produced and the field data. The comparison of the two maps produced by SVM with the geological and mineralization map shows a good restitution of the different classes. Figs. 9 and 10 summarize the results of the evaluation of map accuracy by the confusion matrix. We deduce from the statistical results of this matrix that both maps performed well in terms of describing the spatial distribution of the different types of geological units.
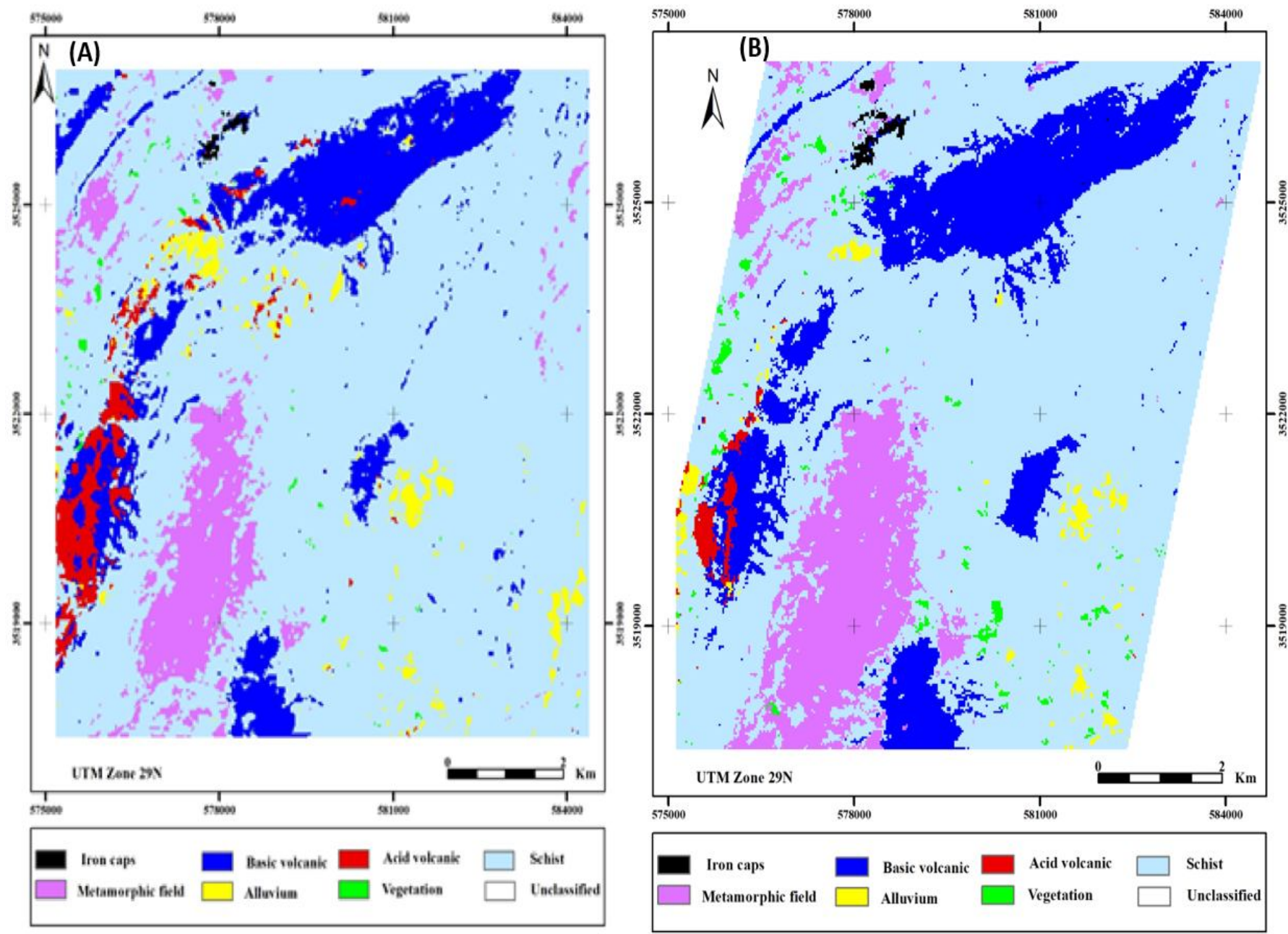

Figure 8: Geological and mineral maps produced: (A) SVM classification of the OLI image, (B) SVM classification of the Hyperion image. 
In addition, the classification of the OLI image showed significant confusion between the two classes of volcanic and an underestimation of iron caps. On the other hand, the classification of the Hyperion image had less confusion and more precision, which may be due to the spectral richness of this sensor. Thus, the results of the precision evaluation by confusion matrix (Figures 9 and 10) showed that the classification of the hyperspectral data slightly outperformed the classification of the multispectral data. Indeed, the SVM classification of the hyperspectral image gave an overall accuracy and a Kappa coefficient of $91.25 \%$ and $93.05 \%$, respectively. For the SVM classification of the multispectral image, the overall precision and Kappa coefficient were 89.24 and $84.36 \%$, respectively. The resulting Kappa coefficients indicate good accuracy in the SVM classification of both images. The obtained results show that SVM is a very efficient classification in geological mapping.

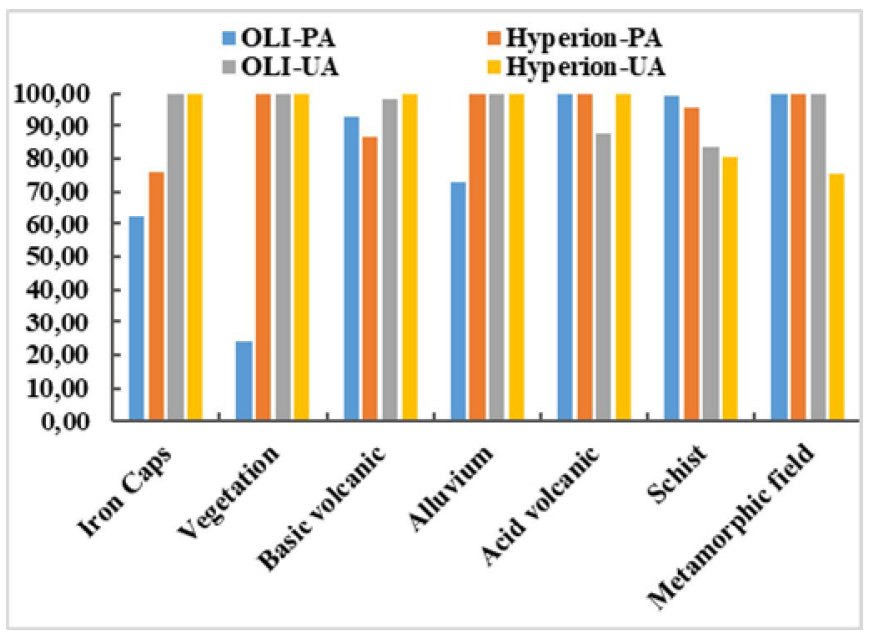

Figure 9: Histogram of the confusion matrix resulting from the validation of the SVM classification of the two images

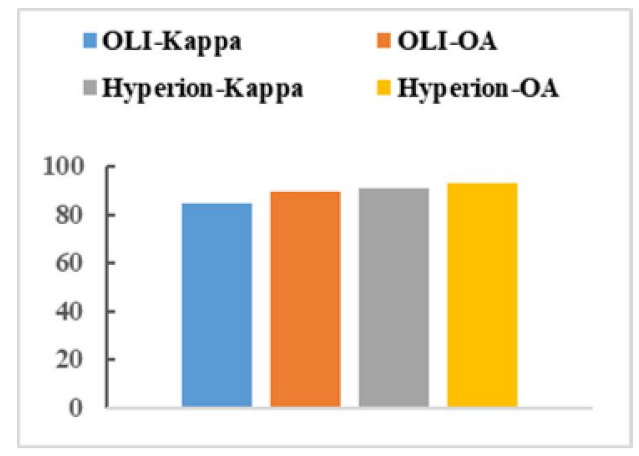

Figure 10: Histogram of the overall accuracy and the kappa coefficient resulting from the validation of the SVM classification of the two images.

\subsection{Band rationing for mapping iron features}

The index developed is based on the iron absorption window at about $850 \mathrm{~nm}$ [51]. After testing several band ratios based on the iron absorption window of existing minerals in the study area (Figure 11).
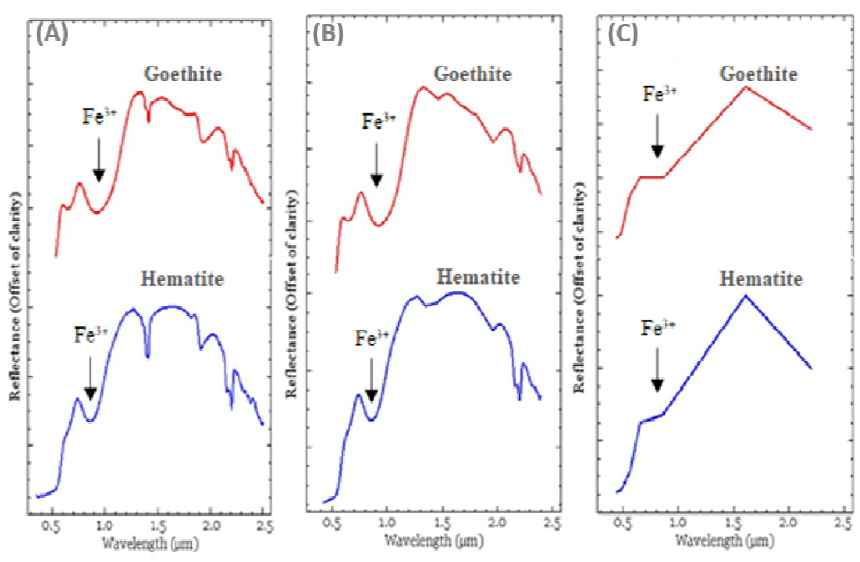

Figure 11: (A) Goethite and Hematite spectra extracted from the USGS (US geological Survey) spectral library, the same minerals resampled to Hyperion bandwidths (B) and Landsat-OLI bandwidths $(\mathrm{C})$.

Based on the iron absorption window of the two minerals (Figure 5 and Figure 11), a normalized iron index calculated by Equation 3 for the Hyperion sensor and by Equation 4 for the OLI sensor was deduced:

$$
\begin{aligned}
& \mathrm{Fe}_{\text {Hyperi on }}=\frac{\text { Band } 109-\text { Dand } 50}{\text { Band } 109+\text { Band } 50} \\
& \text { Fe OLI }=\frac{\text { Band } 6-\text { Band } 5}{\text { Band } 6+\text { Band } 5}
\end{aligned}
$$

With: Band 109 is a short wave infrared band and band 50 is near-infrared band for the Hyperion sensor. Band 5 is near infrared) and band 6 is a short wave infrared band for the OLI sensor.

$\mathrm{Fe}$ Hyperion values are between -1 and 1 , the high values represent ferruginous surfaces. Values above 0.075 represent iron. Concerning $\mathrm{Fe}_{\mathrm{OLI}}$, the values also vary between -1 and 1 , where values above 0.15 represent pixels rich in iron.

The index developed allowed to limit the ferruginous, the iron maps obtained are similar to those obtained by SVM. The results of the collected samples from the random locations were correlated and compared with the corresponding locations in the abundance (Figure12). 

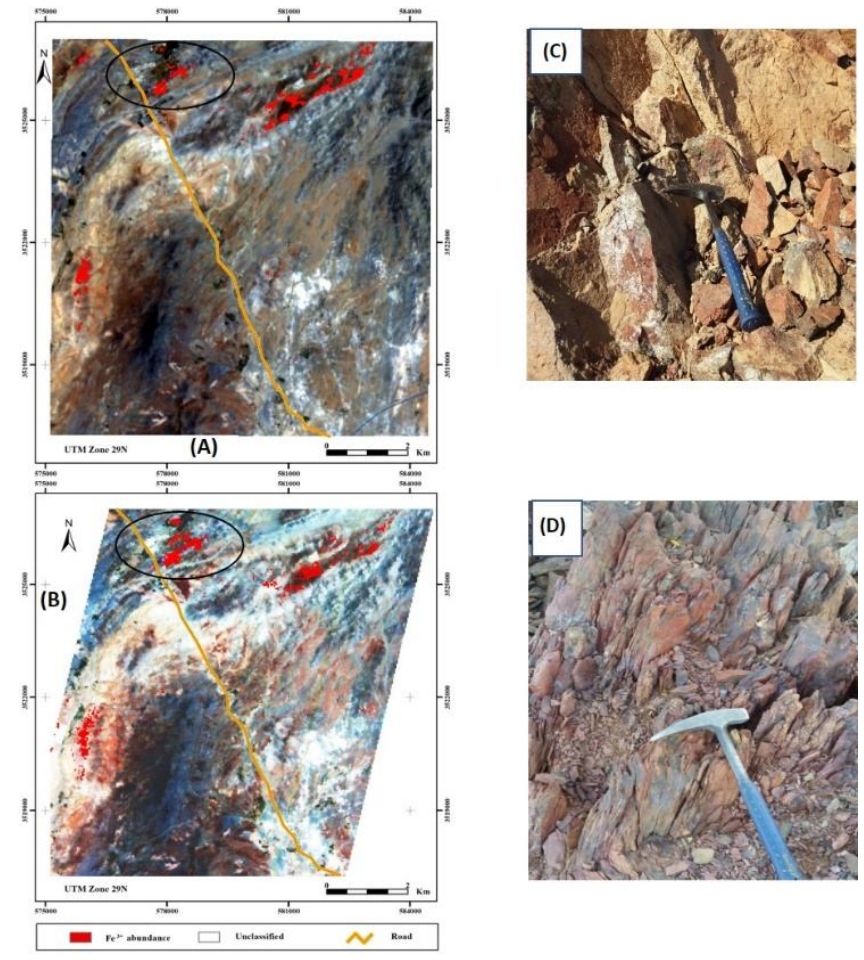

Figure 12: $(\mathrm{A}, \mathrm{B})$ Iron oxide $\left(\mathrm{Fe}^{3+}\right)$ abundance image resulting from Hematite and Goethite band ratio of Landsat OLI and Hyperion respectively, the base for both images is the true composite color of the images. (C) and (D) field photographs showing an example of iron caps over kettara iron deposit.

Indeed, the maps produced by the band ratio or by SVM showed a zone very rich in iron oxides and the schistose dominance of the facies of our study site. In addition, the index of iron $\mathrm{Fe}_{\mathrm{OLI}}$ gave a slightly smaller area of iron compared to $\mathrm{Fe}_{\text {Hyperion. }}$. However, there are several aspects to consider before confirming the most accurate band ratio. The results must be confirmed by additional in-situ geochemistry measurements. The different methods used (iron index, classifications) gave satisfactory results overall and clearly show the different geological and mineralogical units in the region. The results obtained revealed the following points:

Hyperspectral remote sensing has shown its performance in the geological mapping of imaged surfaces. Unlike low spectral resolution sensors.

The machine learning SVM classification allows the identification and mapping of surface geology and mineralogy with high accuracy.

The 850-1300 nm portion of the spectrum has been useful in developing an iron index for mapping areas of iron deposits.

The MNF transformation has allowed the hyperspectral image to be exploited by reducing the number of bands and the noise.

\section{CONCLUSION}

The purpose of this study is geological and mineralogical mapping in the Central Jebilet. Indeed, mapping of different facies and abundant mineralogy has been carried out by SVM classification and band reporting while using two spectrally different systems; First, a hyperspectral system using data from the Hyperion sensor. Second, a multispectral system with an image from the Landsat 8 OLI sensor. The results obtained were evaluated for each system by calculating the overall accuracy. The maps produced provided slightly similar and conclusive results with good accuracies with a clear advantage of hyperspectral data classification. Thanks to multi- and hyperspectral remote sensing, it has been possible to develop updated geological maps at large scales that can be used as a tool to identify potential new sites. In light of the results obtained, it appears that the data and techniques used can be expanded to develop and improve the results. As a result, we propose the following perspectives: (1) Carry out additional ground measurements to gain a better understanding of the spectral response of different rock types; (2) Merge optical satellite and radar images, the latter probably provide more information on surface morphology and texture; (3) Coupling better spatial resolution than OLI and Hyperion sensors with spectral richness is likely to provide more satisfactory results.

\section{REFERENCES}

1. Essaifi, A., Relations entre magmatismedéformation et altération hydrothermale: L'exemple des Jebilet centrales (Hercynien, Maroc). 1995.

2. Essaifi, A. and M. Hibti, The hydrothermal system of Central Jebilet (Variscan Belt, Morocco): A genetic association between bimodal plutonism and massive sulphide deposits? Journal of African Earth Sciences, 2008. 50(2-4): p. 188-203.

3. Aarab, E., Genèse et différenciation d'un magma tholéiitique en domaine extensif intracontinental: exemple du magmatisme pré-orogénique des Jebilet (Maroc hercynien). Marrakech, Maroc, 1995.

4. Huvelin, P., Etude géologique et gîtologique du massif hercynien des Jebilet (Maroc occidental). 1977: Service géologique du Maroc.

5. El Harti, A., et al., Synergie entre la télédétection multispectrale et les données de terrain pour la conception d'un nouveau modèle géodynamique d'ouverture $d u$ bassin paléozoïque des Jebilet centrales (Maroc). Comptes Rendus Géoscience, 2004. 336(14): p. 1311-1320.

6. $\quad$ El Harti, A., et al., Etude spectroradiométrique des roches des Jebilet centrales (Maroc): perspective d'utilisation de la télédétection hyperspectrale pour la cartographie géologique. Télédétection, 2004. 4(3): p. 251-262.

7. $\quad \mathrm{Hu}, \mathrm{B}$. , et al., Hydrothermally altered mineral mapping using synthetic application of Sentinel-2A MSI, ASTER and Hyperion data in the Duolong area, Tibetan Plateau, China. Ore Geology Reviews, 2018. 101: p. 384-397.

8. $\quad$ Adiri, Z., et al., Lithological mapping using Landsat 8 OLI and Terra ASTER multispectral data in the 
Bas Drâa inlier, Moroccan Anti Atlas. Journal of Applied Remote Sensing, 2016. 10(1): p. 016005.

9. Adiri, Z., et al., Mineralogical mapping using Landsat-8 OLI, Terra ASTER and Sentinel-2A multispectral data in Sidi Flah-Bouskour inlier, Moroccan Anti-Atlas. Journal of Spatial Science, 2018: p. 1-25.

10. Soulaimani, A., et al., Application of ASTER remote sensing data to geological mapping of basement domains in arid regions: a case study from the Central Anti-Atlas, Iguerda inlier, Morocco. Arabian Journal of Geosciences, 2014. 7(6): p. 2407-2422.

11. Pour, A., M. Hashim, and Y. Park. Alteration mineral mapping in inaccessible regions using target detection algorithms to ASTER data. in Journal of Physics: Conference Series. 2017. IOP Publishing. https://doi.org/10.1088/1742-6596/852/1/012022

12. Pour, A.B. and M. Hashim, GOLD MINERAL PROSPECTING USING PHASED ARRAY TYPE LBAND SYNTHETIC APERTURE RADAR (PALSAR) SATELLITE REMOTE SENSING DATA, CENTRAL GOLD BELT, MALAYSIA. International Archives of the Photogrammetry, Remote Sensing and Spatial Information Sciences, 2016. 8.

13. Pour, A.B., et al., Evaluation of ICA and CEM algorithms with Landsat-8/ASTER data for geological mapping in inaccessible regions. Geocarto International, 2019. 34(7): p. 785-816.

14. Rajan Girija, R. and S. Mayappan, Mapping of mineral resources and lithological units: a review of remote sensing techniques. International Journal of Image and Data Fusion, 2019. 10(2): p. 79-106.

15. Radziemski, L., et al., Use of the vacuum ultraviolet spectral region for laser-induced breakdown spectroscopy-based Martian geology and exploration. Spectrochimica Acta Part B: Atomic Spectroscopy, 2005. 60(2): p. 237-248.

16. Deaton, B.C. and W.L. Balsam, Visible spectroscopy-a rapid method for determining hematite and goethite concentration in geological materials. Journal of Sedimentary Research, 1991. 61(4).

17. van der Meer, F., Near-infrared laboratory spectroscopy of mineral chemistry: A review. International journal of applied earth observation and geoinformation, 2018. 65: p. 71-78.

18. Chabrillat, S., et al., Use of hyperspectral images in the identification and mapping of expansive clay soils and the role of spatial resolution. Remote sensing of Environment, 2002. 82(2-3): p. 431-445. https://doi.org/10.1016/S0034-4257(02)00060-3

19. Goetz, A., S. Chabrillat, and Z. Lu, Field reflectance spectrometry for detection of swelling clays at construction sites. Field Analytical Chemistry \& Technology, 2001. 5(3): p. 143-155.

20. Kariuki, P.C. and F. Van Der Meer, A unified swelling potential index for expansive soils. Engineering geology, 2004. 72(1-2): p. 1-8.
21. Ulusoy, Y., et al., Prediction of soil cation exchange capacity using visible and near infrared spectroscopy. Biosystems Engineering, 2016. 152: p. 79-93.

22. Waruru, B.K., et al., Rapid estimation of soil engineering properties using diffuse reflectance near infrared spectroscopy. biosystems engineering, 2014. 121: p. 177-185.

23. Adiri, Z., et al., Recent advances in the use of public domain satellite imagery for mineral exploration: A review of Landsat-8 and Sentinel-2 applications. Ore Geology Reviews, 2020: p. 103332.

24. Yitagesu, F.A., et al., Spectral characteristics of clay minerals in the 2.5-14 $\mu \mathrm{m}$ wavelength region. Applied clay science, 2011. 53(4): p. 581-591. https://doi.org/10.1016/j.clay.2011.05.007

25. Hunt, G.R., Spectral signatures of particulate minerals in the visible and near infrared. Geophysics, 1977. 42(3): p. 501-513.

26. Salisbury, J.W., L.S. Walter, and N. Vergo, Availability of a library of infrared $(2.1-25.0 \mu \mathrm{m})$ mineral spectra. American Mineralogist, 1989. 74(7-8): p. 938-939.

27. Gupta, R.P., Remote sensing geology. 2017: Springer.

28. Carli, C., G. Serventi, and M. Sgavetti, VNIR spectral characteristics of terrestrial igneous effusive rocks: mineralogical composition and the influence of texture. Geological Society, London, Special Publications, 2015. 401(1): p. 139-158.

29. Ninomiya, Y. and B. Fu, Thermal infrared multispectral remote sensing of lithology and mineralogy based on spectral properties of materials. Ore Geology Reviews, 2018.

30. Ghulam, A., R. Amer, and T.M. Kusky. Mineral exploration and alteration zone mapping in Eastern Desert of Egypt using ASTER Data. in ASPRS Annual Conference, San Diego, California. 2010.

31. Che, Y. and F. Ye. Research on the remote sensing prospecting model for typical uranium mining area along the Sino-Russian economic corridor. in Fifth Symposium on Novel Optoelectronic Detection Technology and Application. 2019. International Society for Optics and Photonics.

32. Dasgupta, S. and S. Mukherjee, Remote sensing in lineament identification: examples from western India, in Developments in Structural Geology and Tectonics. 2019, Elsevier. p. 205-221.

33. Mwaniki, M.W., M.S. Matthias, and G. Schellmann, Application of remote sensing technologies to map the structural geology of central Region of Kenya. IEEE Journal of Selected Topics in Applied Earth Observations and Remote Sensing, 2015. 8(4): p. 1855-1867.

https://doi.org/10.1109/JSTARS.2015.2395094

34. Van Der Werff, H. and F. Van Der Meer, Sentinel2A MSI and Landsat 8 OLI provide data continuity for geological remote sensing. Remote sensing, 2016. 8(11): p. 883. 
35. EL QAYEDY, J., et al., CARACTÉRISATION LITHOLOGIQUE DU HAUT ATLAS MAROCAIN À L'AIDE DES DONNÉES D'ASTER ET DE MESURES SPECTRALES DE TERRAIN. Télédétection, 2006. 6(2): p. 153-175.

36. Bedini, E., Application of WorldView-3 imagery and ASTER TIR data to map alteration minerals associated with the Rodalquilar gold deposits, southeast Spain. Advances in Space Research, 2019. 63(10): p. 3346-3357.

37. Pal, M.K., T.M. Rasmussen, and M. Abdolmaleki. Multiple Multi-Spectral Remote Sensing Data Fusion and Integration for Geological Mapping. in 2019 10th Workshop on Hyperspectral Imaging and Signal Processing: Evolution in Remote Sensing (WHISPERS). 2019. IEEE.

38. Hunt, G.R., Visible and near-infrared spectra of minerals and rocks: XI. Sedimentary rocks. Modern Geology, 1976. 5: p. 211-217.

39. Hunt, G.R., J.W. Salisbury, and C.J. Lenhoff, Visible and near infrared spectra of minerals and rocks: IX. Basic and ultrabasic igneous rocks. Modern Geology, 1974. 5: p. 15-22.

40. Longhi, I., et al., Spectral analysis and classification of metamorphic rocks from laboratory reflectance spectra in the 0.4-2.5 $\mu \mathrm{m}$ interval: $A$ tool for hyperspectral data interpretation. International Journal of Remote Sensing, 2001. 22(18): p. 3763-3782.

41. Gallie, E., et al., Estimating sulphide ore grade in broken rock using visible/infrared hyperspectral reflectance spectra. International Journal of Remote Sensing, 2002. 23(11): p. 2229-2246.

42. $\mathrm{Lu}, \mathrm{D}$. and $\mathrm{Q}$. Weng, A survey of image classification methods and techniques for improving classification performance. International journal of Remote sensing, 2007. 28(5): p. 823-870.

43. Adiri, Z., et al., Mapping copper mineralization using EO-1 Hyperion data fusion with Landsat 8 OLI and Sentinel-2A in Moroccan Anti-Atlas. Geocarto International, 2018: p. 1-20.

44. Jafari, R. and M.M. Lewis, Arid land characterisation with EO-1 Hyperion hyperspectral data. International Journal of Applied Earth Observation and Geoinformation, 2012. 19: p. 298307.

https://doi.org/10.1016/j.jag.2012.06.001

45. Goodenough, D.G., et al., Processing Hyperion and ALI for forest classification. IEEE transactions on geoscience and remote sensing, 2003. 41(6): p. 1321-1331.

46. Kneizys, F.X., et al., Users guide to LOWTRAN 7. 1988, Air Force Geophysics Lab Hanscom AFB MA.

47. Anderson, G.P., et al. MODTRAN4: Radiative transfer modeling for remote sensing. in Algorithms for multispectral, hyperspectral, and ultraspectral imagery VI. 2000. International Society for Optics and Photonics.
48. Zhang, T., et al., Integrating data of ASTER and Landsat-8 OLI (AO) for hydrothermal alteration mineral mapping in duolong porphyry cu-au deposit, Tibetan Plateau, China. Remote Sensing, 2016. 8(11): p. 890.

49. Rowlands, A. and A. Sarris, Detection of exposed and subsurface archaeological remains using multisensor remote sensing. Journal of Archaeological Science, 2007. 34(5): p. 795-803.

50. Kruse, F.A., Mapping surface mineralogy using imaging spectrometry. Geomorphology, 2012. 137(1): p. 41-56.

51. Magendran, T. and S. Sanjeevi, Hyperion image analysis and linear spectral unmixing to evaluate the grades of iron ores in parts of Noamundi, Eastern India. International Journal of Applied Earth Observation and Geoinformation, 2014. 26: $p$. 413-426.

52. Salaj, S. and R.U.S. Srivastav. Prabhakaran. 2012. Mineral abundance mapping using hyperion dataset in part of Udaipur Dist Rajasthan, India. in 14th Annual International Conference and Exhibition on Geospatial Information Technology and Applications, India.

53. Azizi, H., M. Tarverdi, and A. Akbarpour, Extraction of hydrothermal alterations from ASTER SWIR data from east Zanjan, northern Iran. Advances in Space Research, 2010. 46(1): p. 99109.

54. Boardman, J. and F. Kruse, Automated spectral analysis: a geological example using AVIRIS data, north Grapevine Mountains, Nevada: in Proceedings, ERIM Tenth Thematic Conference on Geologic Remote Sensing. Environmental Research Institute of Michigan, Ann Arbor, MI, pp. I-407-I418, 1994.

55. Green, A.A., et al., A transformation for ordering multispectral data in terms of image quality with implications for noise removal. IEEE Transactions on geoscience and remote sensing, 1988. 26(1): p. 65-74.

56. Wu, X., et al., Real-time implementation of the pixel purity index algorithm for endmember identification on GPUs. IEEE Geoscience and Remote Sensing Letters, 2013. 11(5): p. 955-959.

https://doi.org/10.1109/LGRS.2013.2283214

57. Bioucas-Dias, J.M. A variable splitting augmented Lagrangian approach to linear spectral unmixing. in 2009 First workshop on hyperspectral image and signal processing: Evolution in remote sensing. 2009. IEEE.

58. Jasmine, S.G. and V. Pattabiraman, Improved pure pixel identification algorithms to determine the endmembers in hyperspectral images. Computers \& Electrical Engineering, 2018. 71: p. 515-532.

59. Martínez, P.J., et al., Endmember extraction algorithms from hyperspectral images. Annals of Geophysics, 2006. 49(1).

60. Ouzemou, J.-E., et al., Crop type mapping from pansharpened Landsat 8 NDVI data: A case of a 
highly fragmented and intensive agricultural system. Remote Sensing Applications: Society and Environment, 2018. 11: p. 94-103.

61. Bahari, N.I.S., A. Ahmad, and B.M. Aboobaider. Application of support vector machine for classification of multispectral data. in IOP Conference Series: Earth and Environmental Science. 2014. IOP Publishing.

62. Liu, Q., et al. Classification of Landsat 8 OLI image using support vector machine with Tasseled Cap Transformation. in 2014 10th International Conference on Natural Computation (ICNC). 2014. IEEE.

63. Melgani, F. and L. Bruzzone, Classification of hyperspectral remote sensing images with support vector machines. IEEE Transactions on geoscience and remote sensing, 2004. 42(8): p. 1778-1790. https://doi.org/10.1109/TGRS.2004.831865

64. Vapnik, V., Estimation of Dependences Based on Empirical Data Nauka. 1979, Moscow: Nauka.(in Russian).

65. Syamala, M. and N. Nalini, A Deep Analysis on Aspect based Sentiment Text Classification Approaches. International Journal of Advanced Trends in Computer Science and Engineering (IJATCSE), 2019. 8(5): p. 1795-1801.

https://doi.org/10.30534/ijatcse/2019/01852019

66. Ibrahim, S., M. Rozan, and N. Sabri, Comparative analysis of support vector machine (SVM) and convolutional neural network (CNN) for white blood cells' classification. International Journal of Advanced Trends in Computer Science and Engineering. 8(1.3): p. 394-399.

https://doi.org/10.30534/ijatcse/2019/6981.32019

67. Joshi, P.P., R.H. Wynne, and V.A. Thomas, Cloud detection algorithm using SVM with SWIR2 and tasseled cap applied to Landsat 8. International Journal of Applied Earth Observation and Geoinformation, 2019. 82: p. 101898.

68. Petropoulos, G., et al., Combining ASTER multispectral imagery analysis and support vector machines for rapid and cost-effective post-fire assessment: a case study from the Greek wildland fires of 2007. Natural hazards and earth system sciences, 2010. 10(2): p. 305-317.

69. Petropoulos, G.P., C. Kontoes, and I. Keramitsoglou, Burnt area delineation from a unitemporal perspective based on Landsat TM imagery classification using support vector machines. International Journal of Applied Earth Observation and Geoinformation, 2011. 13(1): p. 70-80.

70. Löw, F., et al., Impact of feature selection on the accuracy and spatial uncertainty of per-field crop classification using support vector machines. ISPRS journal of photogrammetry and remote sensing, 2013. 85: p. 102-119.

71. Joachims, T. Text categorization with support vector machines: Learning with many relevant features. in European conference on machine learning. 1998. Springer.
72. Mather, P. and B. Tso, Classification methods for remotely sensed data. 2016: CRC press. https://doi.org/10.1201/9781420090741

73. ENVI, Version 4.8. 2016, Exelis Visual Information Solutions Boulder, Colorado.

74. El Harti, A., Mode de gisement, étude structurale et contexte de mise en place des corps magmatiques preorogéniques des Jebilet centrales. Sur l'exemple des intrusions de Koudiat Kettara (Maroc Hercynien). 1995, Thèse de doctorat, Université Cadi Ayyad, Faculté des sciences Semlalia .... 